\title{
Optimalisasi fungsi manajemen kepala ruangan dalam supervisi klinik menggunakan alat bantu Google form di rumah sakit di Jakarta
}

\author{
Neni Triana ${ }^{1 *}$, Enie Novieastari ${ }^{1}$, Satinah $^{2}$ \\ 1Program Studi Magister Kepemimpinan dan Manajemen Keperawatan, \\ Fakultas IImu Keperawatan Universitas Indonesia. *Email : nenitriana02@gmail.com \\ 2Bidang Keperawatan RSUP Persahabatan
}

\section{Abstract \\ Utilization of digital technologies as a strategy to optimizing management functions in nursing}

Background: Nursing services need a good management of Nurse Managers to achieve a standardized service quality. Clinical supervision nursing has generally been implemented in hospitals, but its application has not been implemented optimally causing quality improvement not to run continuously.

Purpose: To identify issues of implementation clinical supervision nursing and to develop problem-solving solutions.

Method: The mini project, analysis of results and implementation gap with discussion based on literature review. Problems were analyzed using a fishbone diagram. Problem solving using Plan Do Study Action (PDSA) tools starts from Plan of Action (POA), implementation, evaluation, and follow up. The sample was taken from 5 the inpatient wards.

Results: The problem identification found not optimal the quality of nursing in the planning, monitoring and follow-up phase. Implementation of problem solving by workshop and socialization of guidance, procedure, dictionary and instrument of monitoring clinical supervision nursing with digital tecnology google form. The evaluation result shows that $100 \%$ said the clinical form supervision of digital technology based on google form was very effective and efficient

\section{Keywords: Utilization; Digital technologies; Strategy; Optimizing; Management functions; Nursing}

Pendahuluan: Pelayanan keperawatan memerlukan pengelolaan yang baik dari Manajer Perawat untuk mencapai kualitas pelayanan keperawatan yang sesuai standar. Supervisi klinik keperawatan pada umumnya telah dilaksanakan oleh manajer keperawatan, namun penerapannya belum dilaksanakan secara optimal yang menyebabkan supervisi klinik keperawatan tidak berjalan secara berjenjang.

Tujuan: Mengidentifikasi masalah pelaksanaan supervisi klinik keperawatan di ruang rawat serta mengembangkan solusi pemecahan masalah.

Metode: Berupa mini project serta analisis hasil dan gap implementasi dengan pembahasan berdasarkan literature review. Masalah dianalisis menggunakan diagram fishbone. Penyelesaian masalah menggunakan tools Plan Do Study Action (PDSA) dimulai dari Plan of Action (POA), implementasi, evaluasi, dan tindak lanjut. Sampel diambil dari ruang rawat inap yang terdiri dari 5 Kepala Ruangan.

Hasil: Ditemukan tidak optimalnya supervisi klinik keperawatan pada tahap perencanaan, pemantauan dan tindak lanjut. Implementasi pemecahan masalah berupa sosialisasi dan workshop supervisi klinik keperawatan berbasis teknologi digital google form. Hasil evaluasi menunjukkan bahwa $100 \%$ mengatakan supervisi klinik keperawatan berbasis teknologi digital google form sangat efektif dan efesien.

\section{Kata kunci: Optimalisasi; Fungsi manajemen; Kepala ruangan; Supervisi klinik; Google form}

\section{PENDAHULUAN}

Manajemen keperawatan merupakan koordinasi dan integrasi dari sumber-sumber keperawatan dengan menerapkan proses manajemen untuk mencapai tujuan pelayanan keperawatan. Hal ini tentu perlu didukung oleh seorang manajer (Marquis \& Huston, 2010;
Sulihati, Sjafari \& Listyaningsih, 2018) yang mempunyai kemampuan manajerial yang handal untuk melaksanakan fungsi perencanaan, pengorganisasian, pengarahan dan pengendalian aktivitas-aktivitas keperawatan. Supervisi merupakan bagian dari fungsi pengarahan yang berperan untuk mempertahankan agar segala 
Optimalisasi fungsi manajemen kepala ruangan dalam supervisi klinik menggunakan alat bantu Google form di rumah sakit di Jakarta

kegiatan yang telah terprogram dapat dilaksanakan dengan baik dan lancar. Supervisi secara langsung memungkinkan manajer keperawatan menemukan berbagai hambatan dalam pelaksanaan asuhan keperawatan di ruangan dan bersama dengan staf keperawatan mencari jalan pemecahannya. Supervisi dalam keperawatan bukan hanya sekedar kontrol, tetapi lebih dari itu kegiatan supervisi mencakup penentuan kondisi-kondisi atau syarat-syarat personal maupun material yang diperlukan untuk tercapainya tujuan asuhan keperawatan secara efektif dan efisien (Marquis \& Huston, 2010; Siagian, Gultom \& Munthe 2019).

Kegiatan supervisi yang tidak dilakukan dengan baik akan memberikan dampak bagi kinerja perawat pelaksana juga terjadinya pemberian layanan kesehatan yang menurun atau tidak optimal sehingga dapat muncul kecenderungan akan adanya kejadian yang tidak diharapkan atau nyaris cedera yang bertentangan dengan pasient safety. Penurunan kinerja perawat akan mempengaruhi mutu pelayanan kesehatan (Nainggolan 2010; Prilia, Samsir, \& Pramadewi 2017; Nurcahyani \& Rosdiana 2017). Supervisi adalah proses pengawasan terhadap pelaksanaan kegiatan untuk memastikan apakah kegiatan tersebut berjalan sesuai tujuan organisasi dan standar yang telah ditetapkan. Supervisi dilakukan oleh orang yang memiliki kemampuan yang cakap dalam bidang yang disupervisi. Supervisi biasanya dilakukan oleh atasan terhadap bawahan atau konsultan terhadap pelaksana (Sugiharto, Keliat \& Sri, 2012) manajer keperawatan atau kepala ruang memiliki tanggung jawab dalam pelaksanaan asuhan keperawatan yang efektif serta aman kepada sejumlah pasien dan memberikan kesejahteraan fisik, emosional dan kedudukan bagi perawat (Sugiharto, Keliat \& Sri, 2012; Rahman, Saleh \& Kadar 2019; Laia 216).

Supervisi merupakan upaya untuk membantu pembinaan dan peningkatan kemampuan pihak yang disupervisi agar mereka dapat melaksanakan tugas kegiatan yang telah ditetapkan dengan efektif dan efisien. Supervisi dalam konteks keperawatan dipahami sebagai suatu proses kegiatan pemberian dukungan sumber-sumber yang dibutuhkan perawat dalam rangka menyelesaikan tugas untuk mencapai tujuan yang telah ditetapkan. Pelaksanaan supervisi bukan hanya ditujukan untuk mengawasi apakah seluruh staf keperawatan menjalankan tugasnya dengan sebaik-baiknya, sesuai dengan instruksi atau ketentuan yang telah digariskan, tetapi untuk memperbaiki proses keperawatan yang sedang berlangsung. Kegiatan supervisi yang baik menjadikan seluruh staf keperawatan bukan sebagai obyek tetapi juga sebagai subyek. Perawat diposisikan sebagai mitra kerja yang memiliki ide-ide, pendapat, dan pengalaman yang perlu didengar, dihargai dan diikutsertakan dalam melakukan asuhan keperawatan. Kegiatan supervisi klinik yang tidak dilakukan dengan baik akan memberikan dampak bagi kinerja perawat pelaksana juga terjadinya pemberian layanan kesehatan yang menurun atau tidak optimal sehingga dapat muncul kecenderungan akan adanya kejadian yang tidak diharapkan atau nyaris cedera yang bertentangan dengan pasient safety.

Pelaksanaan supervisi di RSUP Persahabatan belum berjalan dengan optimal hal ini disebabkan banyak faktor salah satunya waktu yang tidak cukup untuk kepala ruangan melakukan supervisi klinik karena banyaknya kegiatan rutinitas diruangan, kadang - kadang kepala ruangan sulit mengatur waktu, tenaga yg ada pd saat waktu yang ditentukan karena berbagai masalah misalnya pasiennya full sehinga banyak tindakan yang dilakukan diruangan dan supervisi akhirnya tidak terealisasi dan juga belum adanya format supervisi klinik sesuai dengan kompetensi keperawatan kekhususan di ruangan sehingga masih menggunakan format supervisi.. Pelaksanaan supervisi klinik masih menggunakan formulir cek list hard copy sehingga hal ini menimbulkan menumpuknya dokumen supervisi klinik keperawatan di ruangan kepala ruangan.

\section{METODE PENELITIAN}

Suatu rangkaian action reseach serta analisis hasil dan gap implementasi dengan berdasarkan literature review (study lapangan, wawancara \& observasi). Kegiatan yang dilakukan dimulai dari identifikasi masalah, kemudian dilanjutkan dengan analisis masalah, penetapan prioritas masalah, penyusunan plan of action, implementasi, serta evaluasi struktur, proses dan hasil. Penentuan ruangan yang dipilih dalam proyek ini dilakukan bersama Bagian Keperawatan. Ruang rawat yang digunakan dalam mini project ini adalah instalasi rawat inap yang terdiri dari ruang perawatan soka

\footnotetext{
Neni Triana'*, Enie Novieastari', Satinah ${ }^{2}$

'Program Studi Magister Kepemimpinan dan Manajemen Keperawatan, Fakultas llmu Keperawatan Universitas Indonesia.

*Email : nenitriana02@gmail.com

${ }^{2}$ Bidang Keperawatan RSUP Persahabatan
} 
Optimalisasi fungsi manajemen kepala ruangan dalam supervisi klinik menggunakan alat bantu Google form di rumah sakit di Jakarta

atas, ruang bedah kelas, Instalasi Bedah sentral ( IBS ), ruang rawat dahlia dan ruang ICU. Dasar pemilihan ruang rawat inap sebagai tempat mini project adalah ruang rawat inap merupakan ruang pelayanan pasien selama 24 jam sehingga kontak perawat dengan pasien lebih banyak. Ruang rawat inap juga merawat pasien yang cukup banyak dengan kasus dan masalah yang kompleks. Proyek ini juga menjadikan Bagian Keperawatan sebagai tempat pelaksanaan kegiatan dan sebagai agen penggerak pelaksanaan fungsi manajemen keperawatan.

Pengambilan data dilakukan melalui wawancara, survei melalui kuisioner, dan observasi lapangan. Data tentang peran dan fungsi top manajer, diambil melalui wawancara terhadap Kepala Bagian Keperawatan dan Kepala Seksi monitoring dan evaluasi. Selain wawancara, metode observasi dilakukan untuk mengidentifikasi ketersediaan dan keterkinian dokumen yang digunakan Bagian Keperawatan dalam pelaksanaan supervisi klinik Keperawatan yang digunakan oleh kepala ruangan.

Observasi lapangan dilakukan di tiga ruang rawat yaitu ruang perawatan dahlia, bedah atas , dan ICU untuk mengidentifikasi penerapan supervisi klinik Keperawatan dan ketersediaan dokumen yang mendukung. Wawancara dilakukan kepada kepala Instalasi IRIN C dan Koordinator IRIN C dan beberapa kepala ruangan yang bertujuan untuk menggali persepsi Kepala Ruangan tentang peran dan fungsi dalam supervisi klinik keperawatan di ruang rawat. Penjelasan tentang tujuan dan topik wawancara diberikan sebelum wawancara ,alat bantu yang digunakan berupa panduan berisi pertanyaan yang bersifat terbuka. Pengumpulan data juga dilakukan dengan penyebaran kuisioner kepada kepala ruangan menggunaka google form. Sampel Kepala Ruangan adalah total sampling dengan jumlah yang bersedia menjadi responden sebanyak 18 orang dari Instalasi Rawat Inap. Hasil pengumpulan data selanjutnya diolah dan dilakukan analisa untuk mencari solusi terhadap masalah yang terjadi.

Pendekatan untuk menyelesaikan masalah ini dengan pendekatan Lewin yang terdiri dari tiga langkah, yaitu unfreezing (pencairan), moving (pergerakan) dan refreezing (pembekuan kembali). Hasil analisis data digunakan dalam penetapan masalah yang diidentifikasi menggunakan diagram fishbone. Hasil identifikasi menjadi dasar menentukan alternatif tindakan penyelesaian. Penyelesaian masalah menggunakan tools Plan Do Study Action (PDSA) dari mulai penetapan Plan of Action (POA), implementasi, evaluasi, dan tindak lanjut. Penyusunan POA dilakukan bersama Bagian Keperawatan dan Kepala Ruangan melalui brain storming. Rencana tindakan disusun mengikuti alur fungsi manajemen sesuai hasil asesmen pada tiap fungsi dan diimplementasikan bersama. Evaluasi dilakukan terhadap 5 Kepala Ruangan. Evaluasi menggunakan kuisioner.

\section{HASIL}

Analisis Masalah Hasil wawancara Bagian Keperawatan menunjukkan kurang optimalnya supervisi klinik keperawatan. Bagian Keperawatan memiliki panduan supervisi klinik Keperawatan. Fungsi perencanaan belum berjalan dengan baik karena belum adanya perencanaan supervisi klinik Keperawatan yang berjenjang. Fungsi pengorganisasian kepala ruangan belum optimal dalam melakukan supervisi klinik Keperawatan karena kendala kesibukan diruang rawat. Fungsi pengarahan dan pengendalian teridentifikasi bahwa belum optimal dilaksanakan. Masalah dari hasil asesmen di atas dianalisis menggunakan diagram fishbone/ ishikawa. merupakan analisis masalah dengan pendekatan analisis sebab akibat menggunakan diagram fishbone menunjukkan belum optimalnya pelaksanaan supervisi klinik keperawatan dari mulai perencanaan sampai pengontrolan. Perangkat tindakan Keperawatan belum di-update sesuai kebutuhan saat ini, Masalah supervisi klinik keperawatan yang seharusnya dilakukan oleh Kepala Ruangan tidak dapat dilaksanakan secara optimal karena sistem supervisi belum terstruktur dan terjadwal.

Hasil analisis fishbone menjadi dasar dalam menyusun rencana tindak lanjut. Rencana tindak lanjut menggunakan kerangka POSAC yaitu fungsi manajemen keperawatan dari mulai perencanaan, pengorganisasian, ketenagaan, pengarahan, dan pengendalian/ pengontrolan. Pendekatan ini diharapkan dapat secara langsung memberikan solusi masalah pengelolaan supervisi klinik keperawatan dan mengoptimalkan fungsi manajemen oleh Bagian Keperawatan dan Kepala Ruangan.

\footnotetext{
Neni Triana'*, Enie Novieastari', Satinah ${ }^{2}$

'Program Studi Magister Kepemimpinan dan Manajemen Keperawatan, Fakultas llmu Keperawatan Universitas Indonesia.

${ }^{*}$ Email : nenitriana02@gmail.com

${ }^{2}$ Bidang Keperawatan RSUP Persahabatan
} 
Optimalisasi fungsi manajemen kepala ruangan dalam supervisi klinik menggunakan alat bantu Google form di rumah sakit di Jakarta

Pada fungsi perencanaan, implementasi yang dilakukan adalah pengembangan dan penyusunan dokumen berupa Panduan Supervisi Klinik Keperawatan berbasis teknologi digital google form. Panduan disusun oleh Bagian Keperawatan dengan melibatkan Kepala Ruangan. Draft panduan dan disampaikan dalam sosialisasi dan workshop, dimana pada kegiatan ini terjadi brainstorming atau tukar pendapat antara Kepala Ruangan yang difasilitasi oleh Bagian Keperawatan. Draft dokumen tersusun $75 \%$ dan akan disempurnakan oleh Kasie monitoring dan evaluasi Keperawatan.

Implementasi fungsi pengorganisasian dan ketenagaan berupa penentuan supervisor supervisi klinik keperawatan di ruang rawat. Tim pemantauan dan evaluasi supervisi klinik keperawatan terdiri dari: Penanggung Jawab : Bidang Keperawata Ketua : Kepala Seksi monitoring dan evaluasi Keperawatan Anggota : Kepala Ruangan. Kepala Seksi monitoring dan evaluasi keperawatan adalah manajer level atas yang merupakan pejabat dibawah Kepala Bagian Keperawatan yang bertanggung jawab dalam penjaminan mutu keperawatan di rumah sakit. Kepala Ruangan merupakan manajer yang mengelola langsung ruang rawat yang bertanggung jawab dalam pelaksanaan peningkatan kualitas keperawatan secara berkelanjutan di ruang yang dikelolanya.

Masalah pada fungsi pengarahan, ditindaklanjuti dengan sosialisasi dan workshop panduan supervisi klinik keperawatan yang dihadiri 37 Kepala Ruangan Kegiatan ini bertujuan melakukan sosialisasi dan diskusi bagaimana melakukan supervisi klinik Keperawatan berbasis teknologi digital google form dan kepala Ruangan diberikan pengarahan tentang materi tentang supervisi klinik keperawatan . Kegiatan pengarahan dilanjutkan dengan pendampingan dan simulasi supervisl klinik berbasis teknologi digital google form.

Implementasi untuk fungsi pengendalian dan pengontrolan, dilakukan penetapan tindakan Keperawatan yang sering dilakukan diruang rawat inap. Evaluasi dilakukan pasca sosialisasi dan workshop dengan melakukan uji coba supervisi klinik Keperawatan pada lima ( 5 ) ruang rawat pada tanggal 12 Desember 2019. Adapun hasil evaluasi melalui kuisioner menunjukan bahwa
$100 \%$ kepala ruangan mengatakan efektif dan efesien dalam melakukan supervisi menggunakan alat bantu Google Form.

\section{PEMBAHASAN}

Supervisi klinik keperawatan merupakan salah satu fungsi pengarahan Kepala Ruangan dalam menjalankan pengelolaan keperawatan di ruang rawat. Hasil asesmen awal dan evaluasi menunjukkan bahwa rumah sakit telah melaksanakan supervisi klinik Keperawatan , akan tetapi compliance penerapannya yang perlu dipertahankan dan dijaga. Supervisi klinik keperawatan dalam penerapannya di rumah sakit RSUP Persahabatan belum dilakukan secara terprogram dan terjadwal, Hal ini sesuai dengan pendapat Cope \& Muray (2017) yang mengemukakan bahwa supervisi adalah suatu aktivitas pembinaan yang direncanakan untuk membantu tenaga keperawatan dalam melakukan pekerjaan mereka secara efektif. Tidak optimalnya supervisi klinik kepala ruangan harus mendapat perhatian yang serius dari bidang keperawatan, mengingat resiko dan dampak yang dapat timbul berkaitan dengan supervisi klinik kepala ruangan yang tidak optimal yaitu pelayanan keperawatan yang tidak berkualitas.. Lebih lanjut dikemukakan bahwa model supervisi klinik keperawatan belum jelas implementasinya di rumah sakit (Cope \& Muray, 2017; Atmaja, Hartini \& Antoro, 2018; Sugiyarto, 2016).

Supervisi merupakan bagian yang penting dalam manajemen serta keseluruhan tanggung jawab pemimpin. Kepala ruangan sebagai ujung tombak tercapainya tujuan pelayanan keperawatan di rumah sakit harus mempunyai kemampuan melakukan supervisi untuk mengelola asuhan keperawatan. Supervisi secara langsung memungkinkan manajer keperawatan menemukan berbagai hambatan/permasalahan dalam pelaksanaan asuhan keperawatan di ruangan dengan memandang secara menyeluruh faktorfaktor yang mempengaruhi dan bersama dengan staf keperawatan untuk mencari jalan pemecahannya. Pelaksanaan supervisi kepala ruangan harus terjadwal dan terprogram dan bila dilakukan secara terus menerus dapat memastikan pelaksanaan asuhan keperawatan sesuai standar praktik Keperawatan.

\footnotetext{
Neni Triana", Enie Novieastari', Satinah ${ }^{2}$

'Program Studi Magister Kepemimpinan dan Manajemen Keperawatan, Fakultas Ilmu Keperawatan Universitas Indonesia.

${ }^{*}$ Email : nenitriana02@gmail.com

${ }^{2}$ Bidang Keperawatan RSUP Persahabatan
} 
Optimalisasi fungsi manajemen kepala ruangan dalam supervisi klinik menggunakan alat bantu Google form di rumah sakit di Jakarta

Seorang manajer keperawatan harus mempunyai kemampuan manajerial yang handal untuk melaksanakan supervisi dan dapat menjalankan peran sebagai perencana, pengarah, pelatih, dan penilai, supervisi klinik berpotensi meningkatkan keahlian dan kemampuan klinik staf yang pada akhirnya akan mempengaruhi kesuksesan pencapaian rumah sakit. Supervisi sebagai alat untuk memastikan atau menjamin penyelesaian tugas sesuai dengan tujuan dan standar (Cope, \& Muray, 2017).

Pendampingan, bimbingan, dan supervisi dari manajemen ke ruang rawat merupakan hal yang dibutuhkan dalam pelaksanaan supervisi klinik keperawatan. Dalam pelaksanaannya supervisi bukan hanya mengawasi apakah seluruh staf keperawatan menjalankan tugasnya dengan sebaik-baiknya sesuai dengan instruksi atau ketentuan yang telah digariskan tetapi juga bagaimana memperbaiki proses keperawatan yang sedang berlangsung. Supervisi dilakukan secara sistematis melalui pengamatan pelayanan keperawatan yang diberikan oleh seorang perawat selanjutnya dibandingkan dengan standar keperawatan. Supervisi klinis merupakan metode yang paling efektif dalam meningkatkan pelayanan keperawatan. Supervisi klinis dalam pelaksanaannya harus berdasarkan Evidence Based Nursing Practice agar pelaksanaan supervisi klinis dapat dilaksanakan secara efektif (Suryaningsih \& Dwiantoro, 2017; Marwiati \& Komsiyah, 2017; Sari, Ngaba \& Lalupanda, 2017). Supervisi klinis salah satu strategi untuk meningkatkan pelayanan kesehatan yang lebih baik (Cruz, Carvalho, \& Sousa, 2014).

Supervisi klinis dapat meningkatkan kepercayaan diri bagi perawat pelaksana (Francis \& Bulman, 2019). Supervisi klinik yang baik dari kepala ruangan dapat meningkatkan pendokumentasian asuhan keperawatan (Nindyanto, Sukesi \& Purnomo, 2013), Hasil studi literatur dinyatakan bahwa kepala ruangan sangat berperan dalam meningkatkan keberhasilan pengendalian infeksi di rumah sakit (Hutahaean, 2018). Berdasarkan penelitian yang menyatakan bahwa ada hubungan antara fungsi supervisi kepala ruangan dengan produktivitas kerja perawat pelaksana (Sihotang, Santosa \& Salbiah, 2016; Basri, 2018).

\section{SIMPULAN}

Supervisi klinik sangat penting dalam pelayanan keperawatan untuk menciptakan pelayanan keperawatan berkualitas tinggi dan kesuksesan pencapaian tujuan rumah sakit. Supervisi klinis keperawatan bertujuan untuk membantu perawat pelaksana dalam mengembangkan profesionalisme sehingga penampilan dan kinerjanya dalam pemberian asuhan keperawatan meningkat. Hasil sosialisasi, workshop, dan simulasi tentang langkah dalam penerapan supervisi klinik keperawatan cukup efektif meningkatkan wawasan Kepala Ruangan tentang supervisi klinik Keperawatan berbasis teknologi digital google form. Persepsi yang baik dari Kepala Ruangan tentang pentingnya supervisi klinik keperawatan menjadi modal awal yang baik untuk melakukan perubahan dan perbaikan dalam menjalankan fungsinya.

Supervisi klinik keperawatan merupakan salah satu fungsi utama manajemen Keperawatan yaitu fungsi pengarahan. Fungsi ini memerlukan dukungan rumah sakit dalam penerapannya. Peran bidang Keperawatan yang paling penting dalam pengendalian kualitas asuhan keperawatan adalah melibatkan staf secara aktif untuk bersama-sama menjamin keberlangsungan penerapan supervisi klinik Keperawatan.

\section{SARAN}

Rumah sakit memberikan dukungan penuh dalam penerapan supervisi klinik keperawatan, mengingat peran perawat sangat penting dalam meningkatkan kualitas asuhan Keperawatan di rumah sakit. Bidang Keperawatan melakukan revisi tindakan Keperawatan sesuai dengan perkembangan Keperawatan saat ini. Melaksanakan supervisi berjenjang dari kepala bidang ke kepala ruangan dan kepala ruangan ke perawat pelaksana agar penerapan supervisi klinik dapat berkesinambungan untuk menjaga kepuasan kerja dan kinerja perawat pelaksana sesuai dengan visi, misi, dan tujuan pelayanan keperawatan. Hasil residensi dapat menjadi studi awal untuk studi lebih lanjut mengenai: Faktor faktor yang mempengaruhi penerapan supervisi klinik keperawatan oleh Kepala Ruangan dan efektifitas Supervisi Klinik Keperawatan Menggunakan Alat Bantu Google Form terhadap kinerja perawat.

\footnotetext{
Neni Triana'*, Enie Novieastari', Satinah ${ }^{2}$

'Program Studi Magister Kepemimpinan dan Manajemen Keperawatan, Fakultas llmu Keperawatan Universitas Indonesia.

*Email : nenitriana02@gmail.com

${ }^{2}$ Bidang Keperawatan RSUP Persahabatan
} 
Optimalisasi fungsi manajemen kepala ruangan dalam supervisi klinik menggunakan alat bantu Google form di rumah sakit di Jakarta

\section{DAFTAR PUSTAKA}

Aprilia, F., Samsir, S., \& Pramadewi, A. (2017). Pengaruh Beban Kerja, Stres Kerja Dan Motivasi Kerja Terhadap Kinerja Perawat Rumah Sakit Islam Ibnu Sina Pekanbaru (Doctoral dissertation, Riau University).

Atmaja, A. D., Hartini, M. I., \& Antoro, L. D. (2018). The Effects Of Clinical Supervision Of Academic Model To Improve The Ability Of Nurses In Applying Patient-Centered Care (PCC) At Hospital. Nurscope: Jurnal Penelitian dan Pemikiran IImiah Keperawatan, 4(1), 4154.

Basri, B. (2018). Hubungan Supervisi Kepala Ruangan Terhadap Kepuasan Kerja Perawat Pelaksana Di Rumah Sakit Imelda Medan. Jurnal maternitas Kebidanan, 3(2), 91106.

Cope, V., \& Murray, M. (2017). Leadership styles in nursing. Nursing Standard, 31(43).

Cruz, S., Carvalho, A. L., \& Sousa, P. (2014). Clinical supervision: Priority strategy to a better health. Procedia: Social and Behavioral Sciences, 112(1), 97-101.

Francis, A., \& Bulman, C. (2019). In what ways might group clinical supervision affect the development of resilience in hospice nurses?. International journal of palliative nursing, 25(8), 387-396.

Hutahaean, S. (2018). Pengembangan fungsi dan peran kepala ruangan dalam pencegahan dan pengendalian infeksi di rumah sakit $X$. Jurnal Akademi Keperawatan Husada Karya Jaya, 4(1).

Laia, S. A. (2016). Hubungan supervisi kepala ruangan dengan pendokumentasian asuhan keperawatan perawat pelaksana di RSUD. Lukas Hilisimaetano Kabupaten Nias Selatan (Doctoral dissertation, Universitas Sari Mutiara Indonesia).
Marquis, B. L., \& Huston, C. J. (2010). Kepemimpinan dan manajemen keperawatan: teori dan aplikasi. Jakarta: EGC.

Marwiati, M., \& Komsiyah, K. (2017). Efektifitas Supervisi Klinis dalam Peningkatan Kompetensi Perawat Pelaksana: Systematic Review. Jurnal Penelitian dan Pengabdian Kepada Masyarakat UNSIQ, 4(3), 213-219.

Nainggolan, M. J. (2010). Pengaruh Pelaksanaan Supervisi Kepala Ruangan terhadap Kinerja Perawat Pelaksana di Rumah Sakit Islam Malahayati Medan.

Nindyanto, S. I. A., Sukesi, N., \& Purnomo, M. A. B. (2013). Pengaruh Supervisi Kepala Ruang Terhadap Dokumentasi Asuhan Keperawatan Di Ruang Rawat Inap RSUD Ungaran. Karya IImiah.

Nurcahyani, E., Widodo, D., \& Rosdiana, Y. (2017). Hubungan Tingkat Stres Kerja Dengan Kinerja Perawat. Care: Jurnal IImiah IImu Kesehatan, 4(1), 42-50.

Rahman, A., Saleh, A., \& Kadar, K. S. (2019). Studi Literature: Analisis Faktor Yang Berhubungan Supervisi Kepala Ruangan Dengan Tingkat Kepatuhan Perawat Di Rumah Sakit. Jurnal Muhammadiyah, 4(2).

Keperawatan

Sari, S. I., Ngaba, A. L., Lalupanda, E. M., \& Aji, A. G. P. (2017). Pengendalian Dan Penjaminan Mutu Pengajaran Melalui Supervisi Klinis. Satya Widya, 33(1), 1-10.

Siagian, H. S., Gultom, R. P., \& Munthe, P. P. (2019). Hubungan Supervisi Kepala Ruangan dengan Kepuasan Kerja Perawat Pelaksana di Ruang Rawat Inap Rumah Sakit Imelda pekerja indonesia. Jurnal IImiah Farmasi Imelda, 3(2), 41-44.

Sitohang, H., Santosa, H., \& Salbiah, S. (2016). Hubungan Fungsi Supervisi Kepala Ruangan dengan Produktivitas Kerja Perawat Pelaksana di Rumah Sakit Umum Daerah dr. Pirngadi Medan. Idea Nursing Journal, 7(1), 13-19.

\section{Neni Triana', Enie Novieastari', Satinah ${ }^{2}$}

'Program Studi Magister Kepemimpinan dan Manajemen Keperawatan, Fakultas llmu Keperawatan Universitas Indonesia.

*Email : nenitriana02@gmail.com

${ }^{2}$ Bidang Keperawatan RSUP Persahabatan 
Optimalisasi fungsi manajemen kepala ruangan dalam supervisi klinik menggunakan alat bantu Google form di rumah sakit di Jakarta

Sugiharto, A. S., Keliat, B. A., \& Sri, T. (2012). Manajemen keperawatan: aplikasi MPKP di rumah sakit. Jakarta: EGC.

Sugiyarto, E. (2016). Gambaran Pelaksanaan Supervisi Keperawatan Dalam Perspektif Perawat Pelaksana Di Rumah Sakit Paru dr. Ario Wirawan Salatiga (Doctoral dissertation, Universitas Muhammadiyah Surakarta).
Sulihati, D., Sjafari, A., \& Listyaningsih, L. (2018). Manajemen pengelolaan rumah sakit umum daerah kota cilegon (Doctoral dissertation, Universitas Sultan Ageng Tirtayasa).

Suryaningsih, D., \& Dwiantoro, L. (2017). Model Supervisi Klinis Yang Dapat Meningkatkan Mutu Pelayanan Keperawatan. 